\title{
Regulatory status of nutraceuticals - is it rationale to rethink?
}

\author{
Tanja Petreska Ivanovska*, Zoran Zhivikj, Lidija Petrushevska-Tozi \\ Institute of Applied Biochemistry, Faculty of Pharmacy, Ss. Cyril and Methodius University, \\ Mother Theresa 47, 1000 Skopje, Republic of North Macedonia
}

\section{Introduction}

The spread of knowledge related to the impact of diet and specific food components have allowed designing healthy food contributing to improved health and overall well-being as well as reduction of chronic diseases. Many studies are focused to an understanding of the potential mechanisms of action of pharmaceutically active substances contained in food. This category named "functional food" or "nutraceuticals" represents a modification of traditional food and it has been confirmed to have a beneficial effect on health beyond nutrition (Corbo et al., 2014). A growing demand for these products which may help to prevent the onset of pathological conditions require proper assessment of their safety, mechanism of action and efficacy with pre-clinical and clinical studies. However, there are specific legislation of nutraceuticals in different countries experiencing challenges with safety and health claim substantiation. Bridging the regulatory gaps by creating an equivocal international regulation is of utmost importance and can help the grey area between pharmaceuticals and food to be overcome.

\section{Current regulations}

The concept of functional foods was first developed in Japan in the 1980s. This concept defined the functional food as the food eligible to reduce the risk of specified health concerns. In 1991, the Japanese Ministry of Health and Welfare launched the first legalization of functional foods under the term "Foods for Specified Health Uses" (FOSHU). In 2001, the Japanese government adopted new regulation system "Foods with Special Dietary Declarations" divided in two categories: Food with nutrient function claims which may contain vitamins and/or minerals and can be distributed without special registration or notification of relevant authorities and FOSHU or food that contains ingredients with health-promoting properties officially recognized to have a positive physiological effect on the human body (Shimizu, 2003). In the EU, the concept of functional foods was firstly introduced within the framework of the research project "Functional Food Science in Europe" (FUFOSE). According to this, food may be considered functional if beneficial effect on one or more functions of the organism beyond its nutritional effect was proven resulting in improve health and well-being and/or reduce the risk of diseases. Functional foods must resemble to conventional foods and be a part of a normal diet showing their beneficial effects when consumed in normal amounts with the diet. In the EU functional food can be classified according to the Regulation (EC) 258/97 of the European Parliament and of the Council on novel foods and novel food ingredients as well by using a Regulation (EC) 1924/2006 on

\footnotetext{
* tpetreska@ff.ukim.edu.mk
} 
nutrition and health claims made on foods. The last one was issued to harmonize different legislations among Member States to guaranty safety and efficacy and to protect the internal market by providing proper information to consumers. Herein, any nutrition or health claim made on food must be scientifically evaluated and approved by the European Food Safety Authority (EFSA) (Bagchi, 2014). These general principles which are also acquired in the legislation of North Macedonia, apply to all foods (functional foods, food supplements, herbal products, probiotics and prebiotics and dietetic foods) for which a statement that the foodstuff contains a beneficial nutritional or physiological substance. While EFSA must authorize in detail any health claim before it is considered at a national or European level prior the new product reaches the market, the FDA in USA is authorized to act against any unsafe product launched on the market (Santini et al., 2018).

In accordance to US regulation, only nutrition and health claims approved by the FDA can be used. The approval by FDA is given in a case the statement complies with safety aspects of a set of regulations different from those of conventional foods and drugs. According to Dietary Supplement Health and Education Act (1994), manufacturer is responsible regarding the safety of the nutraceutical before it is marketed. Apart the food manufacturers, nutrition and health statements may be requested by organizations that promote healthy diet, protect the right of consumers or either consumers themselves. Food and Drug Administration Modernization Act (1997) enabled health and nutrition claims to be authorized based on an authority's statement from the Academy of Sciences or other federal authorities after notifying the FDA at least 4 months before introducing the product on the market. Another legal statement is structure or functional claims which do not refer to diseases, but describe the effect of a component on the structure and function of the body or general well-being. The requirements for these statements are only to be true and do not be misleading or confusing without necessity to be authorized by FDA (Bagchi, 2014).

\section{Future considerations}

The lack of a shared legislation is a big challenge for nutraceuticals globalization because the existence of different legislations can generate confusion resulting in dissimilarity in definition of the same type of product in different countries, leading to confusion among consumers, and eventually to possible misuse. Comprising that no completely effective regulatory system exists in Europe or in the USA, it would be helpful to define nutraceuticals in a new category that differentiates them from food supplements and pharmaceuticals (Santini et al., 2018). In Japan, functional foods are defined according to their use of natural ingredients, whereas in the US, they can also contain ingredients produced with biotechnology, thus confusing information may be the administration of the pharmaceutical form which can be the same for food supplements and nutraceuticals (Santini et al., 2018). The updated European Regulation 2015/2283 define food categories including a definition of food supplements, but EFSA still does not make any distinction between food supplements and nutraceuticals for health claim application on new products. Consumer's needs to create a clear perception also enforced more consistency regarding the regulatory system of nutraceuticals. A uniformly developed regulation system for identification and classification of nutraceuticals at an international level including reliable assessment of quality, efficacy, mechanism of action and safety could potentially benefit both the consumers and the industry.

\section{References}

Bagchi, D., 2014. Nutraceutical and Functional Food Regulations in the United States and Around the World, second ed. Academic Press, USA.

Corbo, M.R., Bevilacqua, A., Petruzzi, L., Pio Casanova, F., Sinigaglia, M., 2014. Functional beverages: the emerging side of functional foods commercial trends research and health implications. Compr. Rev. Food Sci. Food Saf. 13, 1192-1206.

Santini, A., Cammarata, S.M., Capone, G., Ianaro, A., Tenore, G.C., Pani, L., Novellino, E., 2018. Nutraceuticals: opening the debate for a regulatory framework. Br. J. Clin. Pharmacol. 84, 659-672.

Shimizu, T., 2003. Health claims on functional foods: the Japanese regulations and an international comparison. Nutr. Res. Rev. 16, 241-252.

Maced. Pharm. Bull. 66 (Suppl 1) 15 -16 (2020) 